\title{
Sinus pericranii: diagnosis and management in 21 pediatric patients
}

\author{
${ }^{*}$ Marco Pavanello, MD, ${ }^{1}$ llaria Melloni, MD, ${ }^{1}$ Eleonora Antichi, MD, ${ }^{3}$ Mariasavina Severino, MD, ${ }^{2}$ \\ Marcello Ravegnani, MD, ${ }^{1}$ Gianluca Piatelli, MD, ${ }^{1}$ Armando Cama, MD, ${ }^{1}$ Andrea Rossi, MD, ${ }^{2}$ \\ and Carlo Gandolfo, MD²
}

Departments of ${ }^{1}$ Pediatric Neurosurgery and ${ }^{2}$ Neuroradiology, Istituto Giannina Gaslini, Genoa; and ${ }^{3}$ Department of Radiology, Catholic University of the Sacred Heart, Rome, Italy

OBJECT Sinus pericranii (SP) is a rare venous anomaly abnormally connecting the intracranial dural sinuses with the epicranial veins. In the present study the authors aimed to clarify this clinicoradiological entity, define the role of angiography in its preoperative assessment, and suggest a diagnostic-therapeutic flow chart for management purposes.

METHODS The authors retrospectively reviewed the clinical charts and neuroimages of 21 patients with SP. All patients underwent brain MRI, MR venography, and craniocerebral CT. Diagnostic digital subtraction angiography was performed in 19 of 21 patients, and the SPs were categorized as dominant (draining the majority of the intracranial venous outflow) or accessory (draining only a minority of the intracranial venous outflow).

RESULTS SP was median or paramedian in 20 patients and lateral in 1 patient. There were 5 dominant and 14 accessory SPs. The dominant SPs were not treated. Among the patients with accessory SP, 4 were not treated, 2 underwent surgical ligature, and 8 were treated endovascularly (with either transvenous or percutaneous embolization). No complications were observed, and symptoms disappeared after treatment in all cases.

CONCLUSIONS Accepted guidelines or recommendations concerning the management, diagnosis, and treatment of SP are still lacking. The authors define here a diagnostic-therapeutic flow chart, in which angiography plays a crucial role in the classification of SP and choice of the optimal treatment. Only accessory SP is amenable to treatment, whereas dominant SP must be preserved. The endovascular approach is becoming increasingly relevant and has proven to be safe and effective.

http://thejns.org/doi/abs/10.3171/2014.9.PEDS13641

KEY WORDS sinus pericranii; vascular anomaly; scalp vein; endovascular treatment; vascular disorders

$\mathrm{S}$ INUS pericranii (SP) is a rare, benign, venous anomaly consisting of an emissary intradiploic vein deriving from an intracranial sinus, with an increased subgaleal drainage composed of a network of thin-walled veins that form a varix on the external table of the skull..$^{35}$ The anastomotic connections may consist of either a single transosseous vessel or multiple venous structures, which in rare cases can course within the skull bones for several centimeters, causing extensive diploic erosion. ${ }^{34,35,40}$

Sinus pericranii can be isolated (i.e., primitive) or associated with other malformations (i.e., secondary), including craniosynostosis or intracranial venous abnormalities such as dural sinus hypoplasia. ${ }^{30,50}$ The pathogenesis of SP is still unclear; however, its frequent association with intra- cranial developmental venous anomalies (DVAs) and other venous anomalies suggests a congenital predisposition. It has been postulated that transient intracranial venous hypertension in the late embryonic period could lead to the development of venous anomalies, including SP, causing partial regression of bony afferents to the primitive dural sinus. ${ }^{18,33,50}$ An association between head trauma and SP has also been reported; ${ }^{29}$ it has been hypothesized that tearing of emissary veins or direct injury of dural sinuses might allow development of aberrant communications between the epicranial and dural venous systems. ${ }^{5,19,20}$

Although several case reports and small series studies have been published, widespread agreement regarding the diagnostic and therapeutic issues in SP has not yet been

ABBREVIATIONS CDUS = color Doppler ultrasound; DSA = digital subtraction angiography; DVA = developmental venous anomaly; GDC = Guglielmi detachable coil; $M R V=M R$ venography; $\mathrm{SP}=$ sinus pericranii.

SUBMITTED December 3, 2013. ACCEPTED September 15, 2014.

INCLUDE WHEN CITING Published online October 31, 2014; DOI: 10.3171/2014.9.PEDS13641.

DISCLOSURE The authors report no conflict of interest concerning the materials or methods used in this study or the findings specified in this paper.

* Drs. Pavanello and Melloni contributed equally to this work. 
reached..$^{2,43,46}$ Although some authors have described SP as a benign entity that generally does not require treatment, ${ }^{40}$ others have underlined its possible severe complications such as hemorrhage, retrograde sinus thrombosis, and intracranial infections. ${ }^{15}$ Moreover, because of the rarity of this vascular anomaly, there have been no large observational studies that can help us to predict its natural history.

In this report, we describe our clinical experience with 21 pediatric patients harboring SP; to the best of our knowledge, this is the largest case series in the literature. We specifically aimed to do the following: 1) better define this clinical entity by focusing on associated clinical features and other malformations; 2) define the diagnostic role of digital subtraction angiography (DSA) in pretreatment assessment; 3) describe the therapeutic options, their indications, and outcomes; and 4) propose a diagnostic and therapeutic flow chart for management purposes.

\section{Methods}

\section{Patients and Clinical Material}

We retrospectively analyzed a series of 21 patients who presented with a diagnosis of SP to the Istituto Giannina Gaslini between 2004 and 2013. This work received institutional review board approval. The patients were evaluated and treated by a multidisciplinary team that included interventional and diagnostic neuroradiologists, pediatric neurosurgeons, pediatric neurologists, and geneticists.

We reviewed the clinical charts of the patients and noted clinical presentation, external features (i.e., presence of a soft-tissue mass, modifications with postural changes, symptoms related to the SP, skin coloration, etc.), the presence of other vascular abnormalities or cardiac malformations, the presence of developmental delay or other neurological signs, associated syndromes, treatment details, complications of treatment, and outcomes.

\section{Imaging}

Each patient underwent brain MRI and MR venography (MRV) in a 1.5-T system (Intera Achieva 2.6; Philips) and low-dose craniocerebral CT centered on the bony defect in a 64-slice CT scanner (Siemens Somatom 64 Sensation equipped with CARE Dose4D, a technology that decreases the radiation dose $^{42}$ ). Children younger than 6 years and uncooperative patients were sedated during the MR examinations. Brain MRI and MRV evaluations included assessment of the superficial cortical veins adjacent to the $\mathrm{SP}$, associated venous anomalies, and the maturation of the jugular bulbs, as well as the other venous outlets of the brain. Brain CT scans were acquired to detect any associated bone defects and/or scalloping. Brain MR and CT images were also analyzed for the presence of parenchymal abnormalities, cortical malformations, commissural anomalies, and posterior cranial fossa malformations. Seven patients also underwent a color Doppler ultrasound (CDUS) examination; in 4 cases, it was the first imaging modality to be used.

Diagnostic DSA was performed in 19 of 21 patients; for the remaining 2 patients, it was not performed because the parents refused it. We decided to postpone DSA until after the patients were 1 year of age to reduce the risk of complications and to allow for larger amounts of contrast material to increase diagnostic sensitivity. All angiographic procedures were performed under general anesthesia. A 4-Fr catheter (single-hole catheter with little tip curve [e.g., vertebral catheter]) was inserted through a hydrophilic guide in a transfemoral arterial approach. A full diagnostic angiographic study, including selective catheterization of both internal carotid arteries and the dominant vertebral artery, was performed for each patient. The SPs were categorized as: 1) dominant, if the SP and epicranial venous system were the major venous outlets from the intracranial sinus, or 2) accessory, if only a small portion of the intracranial venous blood drained through the SP into the epicranial venous system..$^{18}$ DSA images were also evaluated for the presence of associated intracranial vascular abnormalities and the degree of maturation of the venous outlets of the brain.

\section{Surgical Treatment}

Patients are placed in the prone position. An arciform biparietal skin flap procedure is performed. The SP appears as a vascular, pulsatile bluish lesion that rapidly refills after compression. The vein is located under the pericranium, which is gently dissected from the lesion and preserved. The transosseous vascular connections to the superior sagittal sinus are then carefully coagulated and sectioned, and the epicranial venous components are removed. Finally, the pericranium is carefully closed to permit bony regrowth.

\section{Endovascular Treatment}

Embolization is performed by placing a second 4-Fr catheter through the common femoral vein. By roadmap acquisition, the dominant internal jugular vein is catheterized; then, a coaxial microcatheter is retrogradely navigated to the origin of the SP. The embolization is performed after varicography using Guglielmi detachable coils (GDCs), Onyx, or glue. GDCs are the first choice whenever feasible; other means are preferred in cases of a very small communicating vessel or if the coils do not form a stable cast.

When no arterial or venous continuity is identifiable, percutaneous catheterization is performed through direct puncture of the varix under fluoroscopic guidance with a 19-gauge butterfly needle, with subsequent varicography and eventual embolization. Such a procedure is considered the second choice, because it allows worse control of intracranial migration of the embolizing cast than does the transvenous route.

At the end of the endovascular treatment, bilateral arterial angiography is repeated to confirm SP closure and to rule out complications such as incorrect placement of the embolizing agent.

\section{Follow-Up}

Clinical evaluations that focused on neurological signs and cutaneous features of the SP and brain MRI and MRV were performed 6 months, 1 year, and 2 years after treatment. All but 1 patient completed the follow-up. To assess the long-term outcome after treatment, an additional clinical questionnaire was given to the families. Parents were 
asked to score their cosmetic satisfaction after treatment $(1=$ unsatisfied, 2 = poor satisfaction, $3=$ average satisfaction, $4=$ satisfied, and $5=$ completely satisfied). The parents were also asked whether recurrence of the softtissue mass of the scalp was noted. The mean follow-up duration at the time the questionnaire was administered was 2 years 6 months (range 6 months to 9 years).

\section{Results}

Clinical, neuroradiological, and therapeutic data are summarized in Table 1. Imaging and treatment options are summarized in Fig. 1.

\section{Patient Characteristics and Presentation}

From 2004 to 2013, 21 patients (13 girls and 8 boys) presented to our institution with a diagnosis of SP. The mean age at presentation was 62.5 months (range 1 month to 14 years). All the patients had a nonpulsatile extracranial soft-tissue mass that increased in size when the patient was in the supine and during the Valsalva maneuver and was reduced or disappeared in orthostasis. Two patients (9.5\%) had associated dyschromic changes of the skin. Physical examinations revealed an underlying bony groove of the skull in 3 patients (14.3\%).

Most of the patients (14 of 21 [66.6\%]) had no neurological symptoms related to the SP. Among the symptomatic patients, 4 presented with headaches (19\%), 1 presented with retroauricular SP and ipsilateral pulsatile tinnitus $(4.7 \%)$, and 1 presented with dizziness and vertigo (4.7\%). No patient reported referred local pain. One patient had partial cryptogenic seizures unrelated to the SP that were partially controlled by antiepileptic drugs; MRI showed no anomalies except parietal SP, and electroencephalography revealed diffuse nonlocalizable anomalies enhanced by hyperpnea. The seizures did not resolve after SP treatment. In 3 patients, SP was an incidental finding resulting from clinical and radiological examinations after minor head trauma. No major head traumas were reported.

Three patients had syndromic associations: Noonan syndrome (caused by a mutation in the KRAS gene) with bilateral coronal synostosis, Coffin-Siris syndrome, and $17 q$ deletion syndrome. One asymptomatic nonsyndromic child had a cardiac interventricular defect, aortic coarctation, and blepharophimosis. Three patients (14.3\%) presented with psychomotor delay ( 2 syndromic patients [1 with 17q deletion and 1 with Coffin-Siris syndrome] and 1 nonsyndromic patient with deep venous system hypoplasia).

\section{Imaging}

A CDUS examination was performed in 7 patients and revealed the vascular nature of the lesion in each case, depicting extradiploic serpiginous and dilated veins connected with a transosseous vascular structure.

Brain MRI disclosed the engorged extra- and transcranial veins related to the SP in 19 patients $(90.5 \%)$. In 2 cases, the differentiation from atretic encephalocele or frontonasal venous-capillary malformation could not be elucidated on the basis of MRI alone, and the diagnosis of SP was made on the basis of DSA findings. In 5 non- syndromic children other associated craniocerebral abnormalities were demonstrated and consisted of multiple DVAs, cerebral deep venous system aplasia, Chiari Type I malformation, and cystic leptomeningeal dysplasia.

Computed tomography revealed a bone defect in each patient and associated bone scalloping in 3 patients $(14.2 \%)$.

On the basis of DSA findings, 5 patients had dominant SP and 14 patients had accessory SP. The SP was median in 13 cases and paramedian in 7 cases; in these patients, communication with the superior sagittal sinus occurred through the parietal bone ( $\mathrm{n}=16$ cases), the frontal bone $(n=2$ cases), and at the frontonasal suture ( $n=2$ cases). Only 1 patient had a lateral SP, located in the right retroauricular temporal region and communicating with the sigmoid sinus.

\section{Treatment}

Therapeutic choices were based on the presence of symptoms related to SP, cosmetic issues, associated syndromes or malformations, and DSA findings. Treatment was not provided for the 2 patients whose parents did not allow DSA. One of the patients had Noonan syndrome and bilateral coronal synostosis. In that case, on the basis of the degree of venous engorgement during the Valsalva maneuver, the SP was considered secondary to venous hypertension caused by craniosynostosis. The SP sharply decreased in size after surgical correction of the craniosynostosis and did not require additional treatment. The other patient did not undergo DSA and was not treated because the parents refused it.

By definition, 5 patients with dominant SPs were not treated to avoid compromising intracranial venous outflow (Fig. 2). Of the 14 children with accessory SPs, 4 were not treated. In 2 cases, endovascular and surgical treatments were rejected by the parents, whereas in the 2 remaining patients, the SP spontaneously regressed before treatment was scheduled. In both of these cases, the SP showed complete resolution in the course of 1 year.

Treatment was performed on the remaining $10 \mathrm{pa}-$ tients with an accessory SP. Two patients with a parietal posterior SP were treated surgically. Endovascular treatment was provided for 8 patients: transvenous embolization with GDCs placed along the transosseous channel in 5 patients (Fig. 3), glue embolization by direct puncture in 2 patients, and a transvenous approach combined with a direct puncture (transvenous coiling and percutaneous glue) in 1 patient.

\section{Immediate and Long-Term Outcomes}

We observed no major periprocedural complications in any of the children who received treatment. The 2 patients treated by direct puncture complained during the 1st week after treatment of local pain, which was easily controlled by analgesics. The 2 patients treated by surgical ligature of the SP required a blood transfusion during the procedure.

Preoperative symptoms such as chronic headache, dizziness, and vertigo disappeared after treatment in the course of 6 months. The soft-tissue mass disappeared completely in the surgically treated patients, whereas a mild, almost unnoticeable lump remained in the patients 
TABLE 1. Clinicoradiological features, treatment, and outcomes of patients with SP

\begin{tabular}{|c|c|c|c|c|c|c|c|c|}
\hline $\begin{array}{l}\text { Patient } \\
\text { No. }\end{array}$ & Sex, Age & $\begin{array}{l}\text { SP } \\
\text { Type }\end{array}$ & Site & Clinical Presentation & Comorbidities & Imaging & Treatment & Outcome \\
\hline 1 & M, 2 yrs & $D$ & Rt retroauricular & $\begin{array}{l}\text { Pulsatile tinnitus, soft- } \\
\text { tissue mass }\end{array}$ & - & MRI/CT/DSA & - & Stable \\
\hline 2 & $\mathrm{~F}, 10 \mathrm{yrs}$ & D & Median parietal & Soft-tissue mass & $\begin{array}{l}\text { Coffin-Siris syndrome, } \\
\text { ventricular dilatation, } \\
\text { callosal hypoplasia, } \\
\text { skull base anomaly }\end{array}$ & MRI/CT/DSA & - & $\begin{array}{l}\text { Worsened } \\
\text { neurologi- } \\
\text { cal status }\end{array}$ \\
\hline 3 & $\mathrm{~F}, 1.6 \mathrm{yrs}$ & D & Median parietal & Soft-tissue mass & $\begin{array}{l}\text { Nonsyndromic bilateral } \\
\text { coronal synostosis }\end{array}$ & CT/MRI/DSA & - & - \\
\hline 4 & $\mathrm{~F}, 1 \mathrm{mo}$ & D & $\begin{array}{l}\text { Median fronto- } \\
\text { nasal }\end{array}$ & Soft-tissue mass & $\begin{array}{l}\text { Deep cerebral venous } \\
\text { system hypoplasia, } \\
\text { psychomotor delay }\end{array}$ & CT/MRI/DSA & - & Stable \\
\hline 5 & M, 3 yrs & D & Median parietal & Soft-tissue mass & $\begin{array}{l}\text { 17q deletion, failure to } \\
\text { thrive, hypotonia, psy- } \\
\text { chomotor delay, facial } \\
\text { dysmorphisms }\end{array}$ & CT/MRI/DSA & - & $\begin{array}{l}\text { Worsened } \\
\text { neurologi- } \\
\text { cal status }\end{array}$ \\
\hline 6 & $\mathrm{M}, 4.1 \mathrm{yrs}$ & A & $\begin{array}{l}\text { Rt paramedian } \\
\text { parietal }\end{array}$ & $\begin{array}{l}\text { Headache, dizziness, } \\
\text { soft-tissue mass }\end{array}$ & $\begin{array}{l}\text { Gastroesophageal reflux, } \\
\text { pineal cyst, empty sella }\end{array}$ & CDUS/CT/MRI/DSA & SL & $\begin{array}{l}\text { Permanent } \\
\text { disappear- } \\
\text { ance of SP }\end{array}$ \\
\hline 7 & $F, 2$ yrs & A & $\begin{array}{l}\text { Lt paramedian } \\
\text { parietal }\end{array}$ & $\begin{array}{l}\text { Reddish soft-tissue } \\
\text { mass }\end{array}$ & - & MRI/CT/DSA & - & $\begin{array}{r}\text { Spontaneous } \\
\text { regression }\end{array}$ \\
\hline 8 & $\mathrm{~F}, 4 \mathrm{yrs}$ & A & Median parietal & Soft-tissue mass & - & MRI/CT/DSA & SL & $\begin{array}{l}\text { Permanent } \\
\text { disappear- } \\
\text { ance of SP }\end{array}$ \\
\hline 9 & $\mathrm{~F}, 7 \mathrm{mos}$ & A & Median parietal & Soft-tissue mass & - & CDUS/CT/MRI/DSA & - & - \\
\hline 10 & $\mathrm{~F}, 4.6 \mathrm{yrs}$ & A & $\begin{array}{l}\text { Median fronto- } \\
\text { nasal }\end{array}$ & Soft-tissue mass & Multiple DVAs & CDUS/CT/MRI/DSA & - & Stable \\
\hline 11 & M, 14 yrs & A & Median parietal & $\begin{array}{l}\text { Headache, soft-tissue } \\
\text { mass, skull defect }\end{array}$ & - & CT/MRI/DSA & $\begin{array}{r}\text { ETT \& } \\
\text { EPT }\end{array}$ & $\begin{array}{r}\text { Minimal and } \\
\text { stable re- } \\
\text { sidual SP }\end{array}$ \\
\hline 12 & M, 5 yrs & A & $\begin{array}{l}\text { Lt paramedian } \\
\text { parietal }\end{array}$ & Soft-tissue mass & - & CT/MRI/DSA & - & $\begin{array}{r}\text { Spontaneous } \\
\text { regression }\end{array}$ \\
\hline 13 & F, 5.1 yrs & A & $\begin{array}{l}\text { Lt paramedian } \\
\text { parietal }\end{array}$ & Soft-tissue mass & $\begin{array}{l}\text { Aortic coarctation, blepha- } \\
\text { rophimosis, cardiac } \\
\text { interventricular defect }\end{array}$ & CT/MRI/DSA & ETT & $\begin{array}{l}\text { Permanent } \\
\text { disappear- } \\
\text { ance of SP }\end{array}$ \\
\hline 14 & $\mathrm{~F}, 12 \mathrm{yrs}$ & A & $\begin{array}{l}\text { Lt paramedian } \\
\quad \text { frontal }\end{array}$ & Soft-tissue mass & Chiari Type I anomaly & CDUS/CT/MRI/DSA & EPT & $\begin{array}{l}\text { Permanent } \\
\text { disappear- } \\
\text { ance of SP }\end{array}$ \\
\hline 15 & $F, 2.7$ yrs & A & Median parietal & $\begin{array}{l}\text { Headache, soft-tissue } \\
\text { mass }\end{array}$ & - & CDUS/CT/MRI/DSA & ETT & $\begin{array}{l}\text { Permanent } \\
\text { disappear- } \\
\text { ance of SP }\end{array}$ \\
\hline 16 & $\mathrm{~F}, 12 \mathrm{yrs}$ & A & $\begin{array}{l}\text { Lt paramedian } \\
\text { parietal }\end{array}$ & $\begin{array}{l}\text { Headache, soft-tissue } \\
\text { mass }\end{array}$ & Cavum vergae & CT/MRI/DSA & ETT & $\begin{array}{l}\text { Permanent } \\
\text { disappear- } \\
\text { ance of SP }\end{array}$ \\
\hline 17 & $\mathrm{~F}, 10 \mathrm{mos}$ & A & Median parietal & $\begin{array}{l}\text { Soft-tissue mass, skull } \\
\text { defect }\end{array}$ & - & CDUS/CT/MRI/DSA & ETT & $\begin{array}{l}\text { Permanent } \\
\text { disappear- } \\
\text { ance of SP }\end{array}$ \\
\hline 18 & $\mathrm{~F}, 12.6 \mathrm{yrs}$ & A & Median parietal & Soft-tissue mass & Seizures & CT/MRI/DSA & ETT & $\begin{array}{l}\text { Permanent } \\
\text { disappear- } \\
\text { ance of SP }\end{array}$ \\
\hline 19 & M, 14 yrs & A & Median frontal & $\begin{array}{l}\text { Soft-tissue mass, skull } \\
\text { defect }\end{array}$ & Leptomeningeal dysplasia & CT/MRI/DSA & EPT & $\begin{array}{l}\text { Permanent } \\
\text { disappear- } \\
\text { ance of SP }\end{array}$ \\
\hline
\end{tabular}


TABLE 1. Clinicoradiological features, treatment, and outcomes of patients with SP (continued)

\begin{tabular}{|c|c|c|c|c|c|c|c|c|}
\hline $\begin{array}{l}\text { Patient } \\
\text { No. }\end{array}$ & Sex, Age & $\begin{array}{l}\text { SP } \\
\text { Type }\end{array}$ & Site & Clinical Presentation & Comorbidities & Imaging & Treatment & Outcome \\
\hline 20 & M, 6 mos & - & $\begin{array}{l}\text { Rt paramedian } \\
\text { parietal }\end{array}$ & Soft-tissue mass & $\begin{array}{l}\text { Noonan's syndrome, } \\
\text { thoracic lymphatic } \\
\text { dysplasia, tricuspid } \\
\text { insufficiency, coronal } \\
\text { synostosis }\end{array}$ & $\mathrm{MRI} / \mathrm{CT}$ & CR & $\begin{array}{l}\text { SP decreased } \\
\text { in size at } \\
\text { further } \\
\text { follow-ups }\end{array}$ \\
\hline 21 & $\mathrm{M}, 9 \mathrm{mos}$ & - & Median parietal & Bluish soft-tissue mass & - & CDUS/MRI/CT & - & - \\
\hline
\end{tabular}

treated endovascularly, but there were no cosmetic issues or additional growth of this lump on follow-up. Bone regrowth was observed in the 2 surgically treated patients but not in the patients treated endovascularly. No signs of recurrence were present at clinical or radiological followup 6,12 , and 24 months after treatment, and the patients did not experience any new neurological symptoms. The patient treated by a combined endovascular and percutaneous approach presented a minimal residual SP, which was stable on MRI follow-up and did not require additional treatment. Parental interviews revealed overall satisfaction with the treatment. The mean $( \pm \mathrm{SD})$ cosmetic satisfaction score was $4.2 \pm 0.74$. No recurrences were reported.

The outcomes of the 4 untreated accessory SPs were variable; 2 accessory SPs resolved spontaneously before treatment was scheduled. We lost to follow-up 1 of these patients, whose parents refused treatment or additional care. The remaining patient exhibited stable neurological conditions, and follow-up imaging results were unchanged. The outcomes of the 5 dominant SPs highly depended on underlying clinical conditions and comorbidities. The 1 patient harboring a 17q deletion and the 1 with Coffin-Siris syndrome showed progressive neurological and psychomotor deterioration because of their baseline conditions. One patient was lost to follow-up. The remaining 2 patients showed a stable SP volume. Of the 2 patients who did not undergo DSA, 1 was lost to follow-up and 1 underwent surgical correction of bilateral coronal synostosis, which led to a gradual regression of the SP.

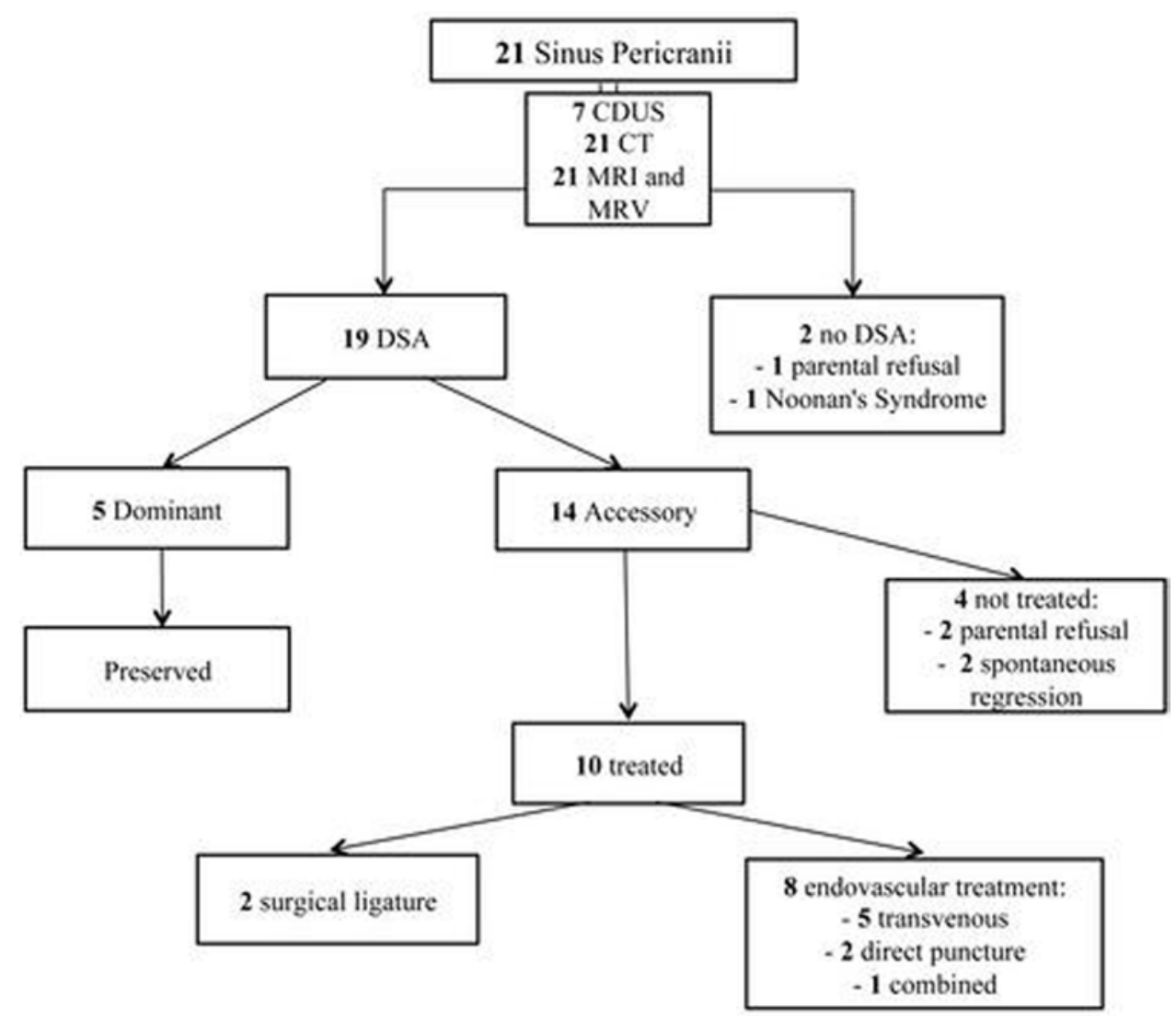

FIG. 1. Scheme of the study showing the details of diagnosis and treatment. 

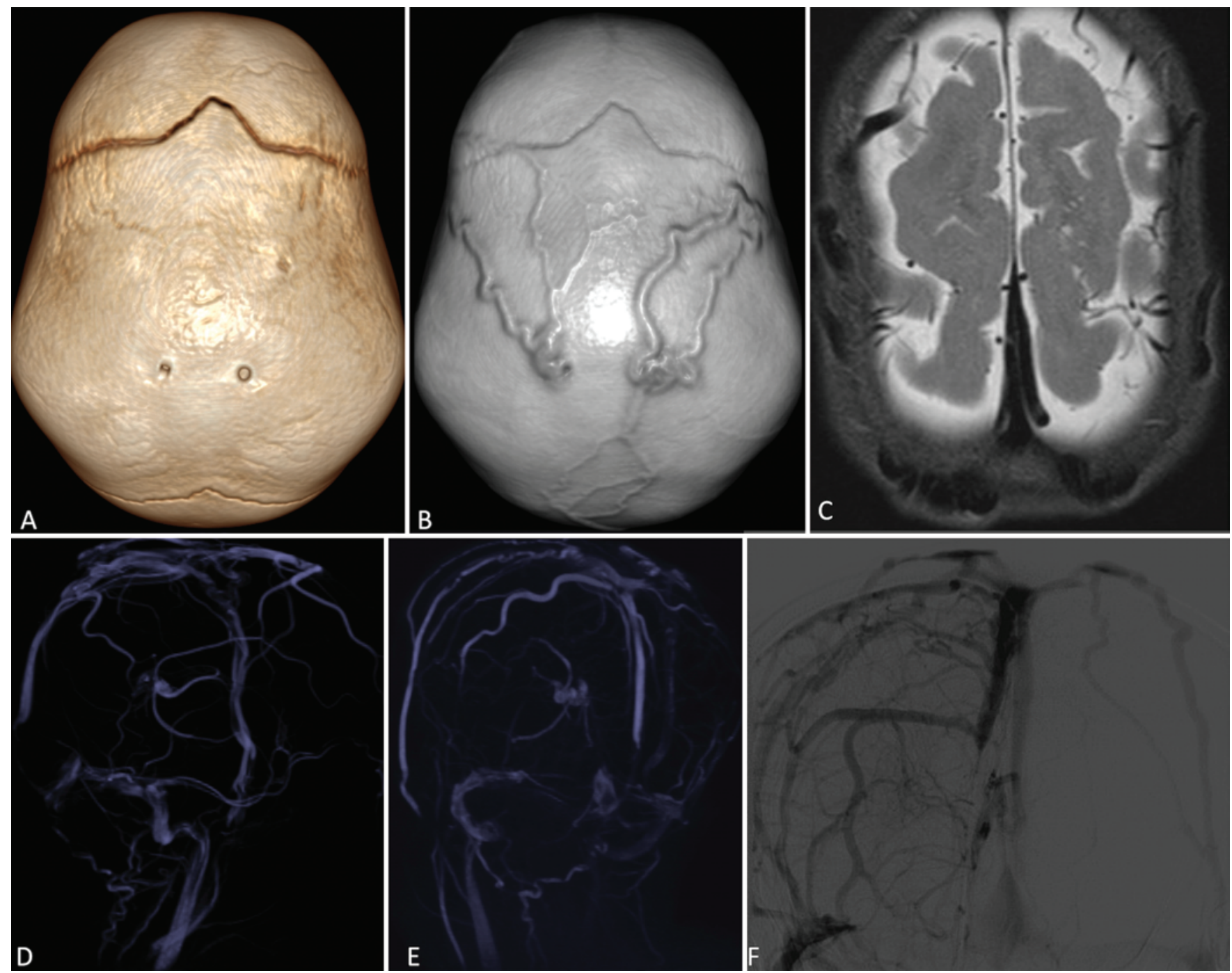

FIG. 2. Patient 5 with dominant SP. A and B: Contrast-enhanced 3D CT reconstruction images showing 2 holes in the parietal bone (A) and the epicranial venous varices on the vertex (B). C: Axial T2-weighted MR image depicting the bilateral venous varices on the vertex as a flow void. D and E: 2D time-of-flight MRV images, lateral (D) and posterior oblique (E) views, revealing wide subcutaneous venous structures on the vertex and hypoplasia of intracranial venous system (lower third of superior sagittal sinus stenosis and straight sinus hypoplasia, severe bilateral transverse sinus hypoplasia). F: Anteroposterior DSA image, venous phase, showing a dominant biparietal SP, which constitutes the main venous outflow of the intracranial venous system and of the right DVA. Figure is available in color online only.

\section{Discussion}

In this paper, we discuss our 9-year single-center experience with 21 patients with SP. Our sample is very heterogeneous in terms of age and clinical presentation, as well as clinical management and treatment. We found a slight female predominance (62\%); in accordance with the literature, ${ }^{4} 95 \%$ of the SPs were median or paramedian, located over the parietal or frontal bone. Off-midline locations are reportedly rare, ${ }^{23,28,34,44}$ and indeed, we found only 1 such case. In our series, as well as in previously reported studies, ${ }^{1}$ SP typically presents as a soft mass that enlarges during crying, the Valsalva maneuver, and when the individual is supine. Evaluation of volume changes after manual jugular vein compression is a useful confirmatory test. The mass can be associated with reddish or bluish skin dis- coloration and hyperemia. Most patients are asymptomatic and show no other clinical signs. Some patients, however, complain of specific symptoms such as headache, nausea, dizziness, and vertigo., ${ }^{2,14,39}$ Local pain is sometimes reported. ${ }^{1}$ Rarely reported are severe complications such as increased intracranial pressure, bradypnea, and bradycardia ${ }^{45}$ caused by hemorrhagic or thrombotic complications or head trauma ${ }^{1,2,8,21,35,39,50}$ (Table 2). In the literature, there is 1 report of SP indirectly causing epileptic seizures because of transient impairment of blood flow in the superior sagittal sinus and local changes in metabolism..$^{21}$ One of our patients had cryptogenic partial epilepsy; however, SP was the only visible anomaly on imaging, and the seizures did not regress after SP treatment. Therefore, we could not establish any pathophysiological association between the 2 conditions. Finally, SP has been reported in association 

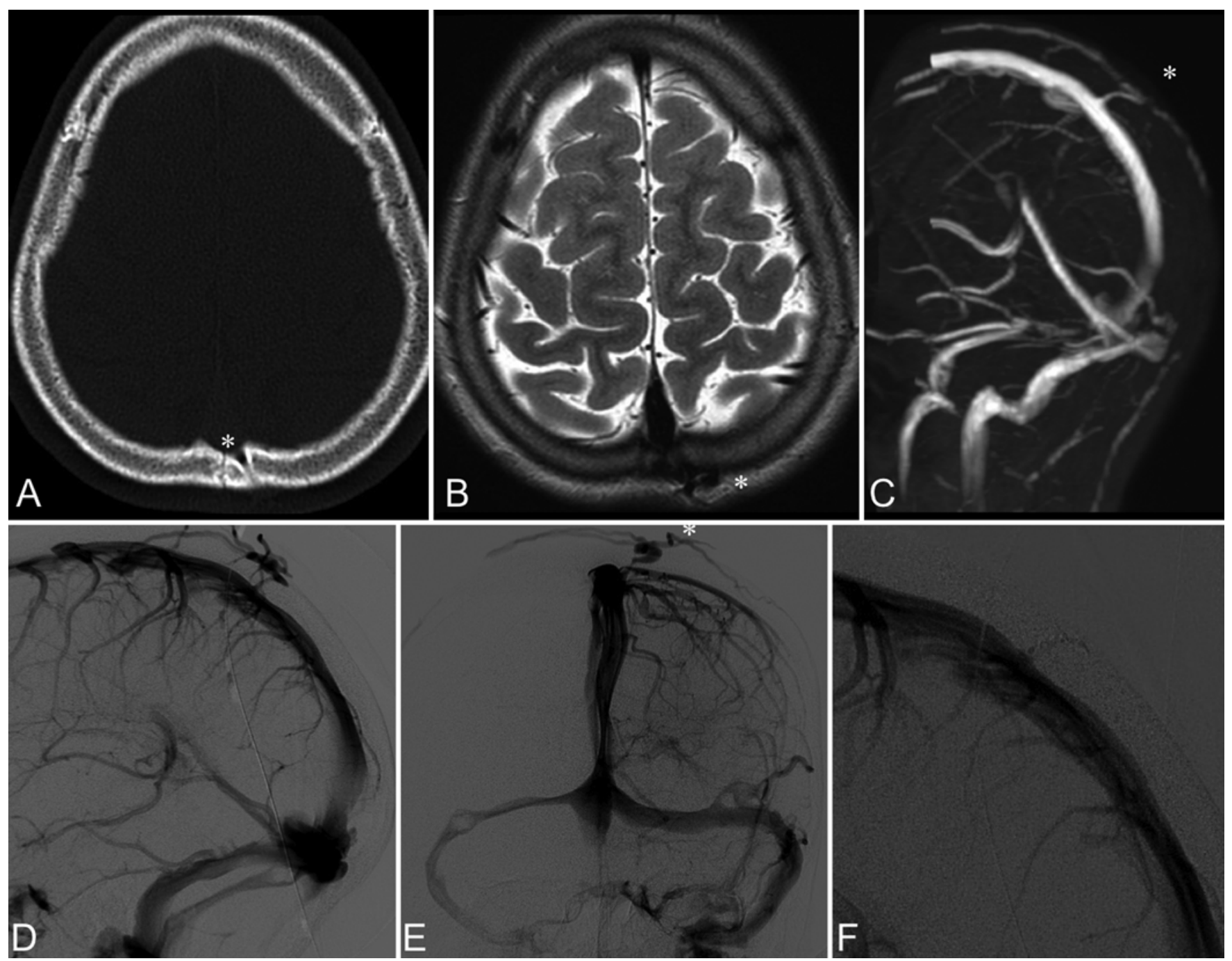

FIG. 3. Patient 16 with accessory SP. A: Axial CT scan revealing a defect in the left parietal bone (asterisk). B and C: Brain images demonstrating varices as a flow void on the axial T2-weighted image (B, asterisk) and a venous structure communicating with the superior sagittal sinus on lateral 2D time-of-flight MRV image (C, asterisk). D-F:. Venous-phase DSA studies, lateral (D and F) and anteroposterior (E) views, demonstrating an accessory SP (asterisk). F: Correct placement of coils.

with several malformations and syndromes, as shown in Table 3. $5,6,9,10,16,17,24,26,27,31,32,47,50$

The natural history of SP is not clearly understood. Although SP is generally considered benign, the outcome may not be predicted easily. Most cases remain stable in the long term, ${ }^{1}$ but the psychological impact on the patients' quality of life may be relevant. Moreover, complications such as intracranial hemorrhage, air embolism, and sinus thrombosis have been reported to occur spontaneously or after head trauma. ${ }^{1}$ In our experience with 2 intraosseous SPs, there was such a wide bone erosion that the risk of significant complications in case of local trauma was considered to be high. Finally, we observed 2 cases of spontaneous regression; although few similar cases have been reported in the literature, ${ }^{11,38}$ it may not generally be considered a likely outcome.

Imaging of SP involves several steps. Color Doppler ultrasonography is a readily available, first-line diagnostic tool that may disclose the vascular nature of the lesion, although the transcranial vessel may not be detected easily, and the intracranial communication with the dural sinuses is usually missed..$^{25,49}$ For these reasons, brain MRI should be performed every time that CDUS confirms the suspicion of a vascular anomaly. Brain MRI with MRV allows differentiation from other conditions presenting with a palpable skull mass, such as meningoencephaloceles, eosinophilic granulomas, epidermoid and dermoid cysts, growing fractures, and scalp abscesses. Moreover, MRI detects the typically congested epicranial veins and the possible associated venous anomalies (including dural sinus hypoplasia). Differentiation from other vascular lesions, such as arteriovenous fistulas or subepicranial varices (which are not connected to dural sinuses), may be more complex in some cases. ${ }^{3,12}$ Moreover, brain MRI may fail to reveal the transcranial vein when the amount of flow is not conspicuous. ${ }^{4}$ Cranial unenhanced CT with bone windowing is usually not able to depict transcranial vessels, ${ }^{14}$ but it provides complementary information re- 
TABLE 2. Symptoms and complications associated with SP

\begin{tabular}{clc}
\hline Minor Symptoms & \multicolumn{1}{c}{ Severe Symptoms } & \multicolumn{1}{c}{ Complications } \\
\hline Local pain & $\begin{array}{c}\text { Increased intracranial pres- } \\
\text { sure }\end{array}$ & Traumatic air emboli \\
\hline Nausea & Bradypnea & Massive hemorrhage \\
\hline Headache & Bradycardia & Severe cardiac failure \\
\hline Dizziness & Ataxia, hearing loss & \\
\hline & Epileptic seizures & \\
\hline
\end{tabular}

garding the location, size, shape, and margins of the bony communication, which enables us to choose the optimal size of the coils that should be used to embolize the vessel ${ }^{7}$ and to select which side to navigate the catheter toward to reach the superior sagittal sinus. To minimize the patient's radiation exposure, we usually perform low-dose CT with automatic exposure control centered on the skull defect.

Digital subtraction angiography is the gold standard for the diagnosis of SP, ${ }^{18}$ not only does it detect the location, size, and course of the venous anomaly, but it also provides information on the flow dynamics of the lesion. Moreover, DSA can determine the safest way to endovascularly reach the SP, revealing peculiar conditions such as unilateral hypoplasia or agenesis of the transverse and sigmoid sinuses, longitudinal septations of the sagittal superior sinus, and eccentric outflow of the SP, which may influence the physiopathology and the possible treatment. It is important to note that DSA also enables us to discriminate between the 2 basic SP patterns, dominant (if the main stream of contrast material uses the SP to drain the brain, bypassing the usual venous outlets) and accessory (if only a small part of the venous outflow occurs through the extradiploic vessels); in keeping with the Gandolfo classification,,$^{18}$ such discrimination represents the main factor to consider for management decisions. In fact, a dominant SP is the main outflow of the intracranial venous system and therefore must be preserved; the paramount importance of this condition must be clarified to the family and referring pediatrician alike, because incidental or iatrogenic closure of a dominant SP may cause intracranial hypertension, cerebral hemorrhage, and possibly death. ${ }^{18}$ On the other hand, an accessory SP does not contribute significantly to intracranial venous outflow and therefore can be treated safely. Finally, DSA may ascertain the diagnosis of SP in the unlikely event that MRI or CT fail to depict the nature of the lesion. In our series, MRI failed to ascertain the diagnosis of SP in 2 cases. Although the small number of patients prevented us from obtaining significant statistical data, we suggest that DSA has a higher ability to detect SP than other modalities.

Sinus pericranii associated with craniosynostosis poses additional management concerns. Single-stage surgery for both conditions has been previously described, ${ }^{30}$ although in many cases SP can be secondary to venous hypertension related to craniosynostosis and therefore may improve, or even disappear, after surgical treatment of craniosynostosis, as we found in 1 case. In such cases, we suggest that craniosynostosis should be treated first, and closure of the residual SP may be contemplated at a later stage, if required.

There presently is no consensus regarding the indications for treatment of accessory SPs, although authors agree that it is possible to treat this anomaly without severe morbidity or interference with brain circulation. ${ }^{22,40} \mathrm{In}$ particular, available data on the natural history of SP are still scarce. Most SPs remain stable in size and flow dynamics over years. There are few reports on spontaneous regression, as we observed in 2 cases, or on rare dramatic complications including venous thrombosis and intracranial hemorrhage. Studies on larger series are awaited to identify prognostic factors for predicting which subtypes of accessory SP will regress, remain stable, or progress over time.

We believe that several factors need to be considered for management purposes. First, neurological symptoms related to the SP should be treated promptly. In our experience, persistent headaches that were resistant to painkillers and not explained by any comorbidities were considered a posteriori to be a manifestation of SP, because they regressed after treatment. On the basis of this experience, we suggest that headaches may be an alerting symptom in patients with SP, as they could indicate intracranial hypertension or, more simply, initial brain dysfunction due to the vascular anomaly. Second, even asymptomatic, stable SPs

TABLE 3. Malformations and syndromes associated with SP

\begin{tabular}{llll}
\hline \multicolumn{1}{c}{ Associated Syndromes } & \multicolumn{1}{c}{ Vascular Anomalies } & Meningocerebral Anomalies & $\begin{array}{c}\text { Systemic Anomalies } \\
\text { or Malformations }\end{array}$ \\
\hline Crouzon syndrome & Vein of Galen hypoplasia & Meningocele & Systemic hemangiomas \\
\hline Apert syndrome & DVA & Cerebellar hemangioma & Esophageal atresia \\
\hline Trigonocephaly & VGAM & Hemangioma retina & Cutis aplasia congenita \\
\hline Oxycephaly & DSM & Atretic cephalocele & \\
\hline Blue-rubber bleb nevus syndrome & Intraosseous AVM & Corpus callosum aplasia & \\
\hline Von Hippel-Lindau syndrome & Shunt DSM & & \\
\hline CAMS-III & Aneurysmal malformation of internal & & \\
& cerebral vein & & \\
\hline Hunter syndrome & Cavernous hemangioma & & \\
\hline PHACE syndrome & & & \\
\hline
\end{tabular}

CAMS = craniofacial arteriovenous metameric syndrome; DSM = dural sinus malformation; PHACE = posterior fossa of the brain, arterial anomalies, cardiac anomalies, and eye anomalies; VGAM = vein of Galen aneurysmal malformation. 
can cause psychological concerns because of the skull deformity and cosmetic issues, especially in adolescents, and may justify treatment. Third, although the rate of severe complications cannot be reliably estimated because of the rarity of the condition, affected children may be at risk for intracranial hemorrhage or dural sinus thrombosis after even minor head trauma, ${ }^{15,41}$ posing a risk of severe or fatal complications. Our approach was to observe the evolution of asymptomatic accessory SPs for a variable amount of time depending on patient age at diagnosis (around 4-12 months). If the SP spontaneously regressed or showed a trend of regression, we kept waiting and watching. If, after 1 year, the SP was unchanged or even worsened, or there were new symptoms, we proposed treatment in view of the facts that the natural history of SP is not fully understood, there is a potential risk of severe complications after minor trauma, and cosmetic issues may cause psychological problems (Fig. 4).

Consensus in the scientific community is also lacking about the choice of the optimal modality of treatment, which may include surgical ligature, endovascular transvenous or direct puncture approaches, and combined ap- proaches. There are reports in the literature on a few small series of patients treated surgically, ${ }^{13,36}$ whereas conservative treatment has been described in some isolated cases. ${ }^{1,40}$ Since 2009, a few cases of endovascular treatment have been reported, ${ }^{7,22,37}$ but no large series exists yet. In the past 9 years, our management strategy for SP has progressively changed. At the beginning of our experience, we were still developing the necessary neurointerventional skills, and we tended to prefer the surgical approach. With time, we realized that patients treated endovascularly needed shorter hospital stays and had less infection risks and blood loss. We therefore suggest the endovascular approach as the preferential method for treating isolated accessory SP, whereas the classical surgical treatment should be reserved for complex cases in which the SP is associated with other anomalies or malformations, for cases of intracranial hemorrhage, or after failure of endovascular treatment. Moreover, it is possible to perform diagnostic DSA and treatment in the same session, thereby reducing radiation exposure, anesthesiology risks, and contrast material administration. Recent reports on the safety of pediatric DSA and pathology-specific intervention dem-

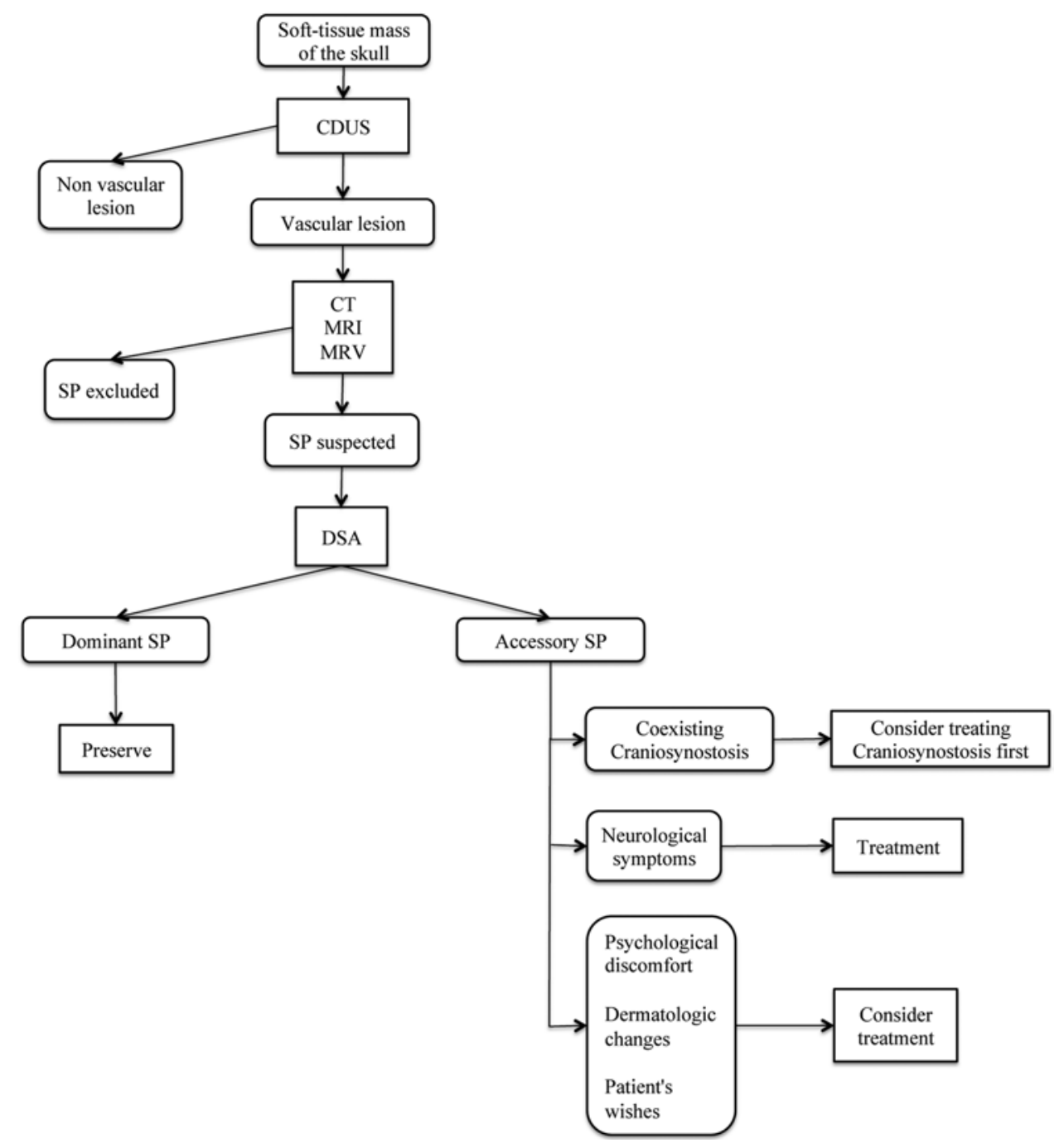

FIG. 4. Diagnostic and decisional flow chart. 
onstrated minimal procedural morbidity, confirming that DSA can be performed in the pediatric age group safely within an interventional tertiary neuroradiology center. ${ }^{48}$

The immediate and long-term outcomes of treated patients were satisfactory. Neurological symptoms directly related to SP, such as headache, vertigo, and ataxia, invariably disappeared after treatment. None of the patients experienced posttreatment complications or recurrence, and the cosmetic result was satisfactory in each case.

On the basis of this experience, we have devised a diagnostic-therapeutic flow chart that may support pediatricians, neurosurgeons, and neuroradiologists in the management of SP (Fig. 4). The first step of diagnosis should be a CDUS examination, aimed to confirm the vascular nature of the lesion, followed by MRI with MRV to confirm the diagnosis of SP. CT scanning is also required to depict the underlying bone defect. DSA confirms the diagnosis, defines the vascular pattern as dominant or accessory, and guides treatment whenever necessary. Dominant SPs should not be treated and require lifelong monitoring, whereas accessory SPs can usually be treated safely. Therapeutic choices should be based on the presence of neurological symptoms and psychological discomfort caused by deformity and cosmetic issues. We prefer retrograde transvenous embolization whenever feasible, whereas direct puncture is performed only when the vascular anatomy is not completely clear or when the operator fails to catheterize the origin of the SP because of concurrent intracranial venous abnormalities. Surgery, either alone or combined with an endovascular approach, should be reserved for selected cases, such as those in which complex $\mathrm{SP}$ is associated with other vascular anomalies or in cases of complications such as hemorrhage.

Among the several limitations of the present study, the small sample size is certainly relevant, as is its retrospective nature. However, it is difficult to recruit large patient series for such a rare condition. Multicenter studies are awaited to provide a larger evidence base regarding management of SP.

\section{Conclusions}

Because of its rarity, the exact nature and management of SP are debated, and agreement on guidelines or recommendations for management and therapeutic choices is still lacking. Neuroimaging plays a critical role in the diagnosis of this uncommon condition. DSA is pivotal for the categorization of SPs as dominant or accessory, which in turn informs management choices. Only accessory SPs are amenable to treatment, whereas dominant SPs must be preserved. Endovascular embolization is a safe and effective treatment option.

\section{References}

1. Akram H, Prezerakos G, Haliasos N, O’Donovan D, Low H: Sinus pericranii: an overview and literature review of a rare cranial venous anomaly (a review of the existing literature with case examples). Neurosurg Rev 35:15-26, 2012

2. Anegawa S, Hayashi T, Torigoe R, Nakagawa S, Ogasawara T: Sinus pericranii with severe symptom due to transient disorder of venous return-case report. Neurol Med Chir (Tokyo) 31:287-289, 1991
3. Asano K, Sobata E, Kubo O: Subepicranial varix mimicking sinus pericranii: usefulness of three-dimensional computed tomography angiography and bone window computed tomography-case report. Neurol Med Chir (Tokyo) 40:467-471, 2000

4. Azusawa H, Ozaki Y, Shindoh N, Sumi Y: Usefulness of MR venography in diagnosing sinus pericranii: case report. Radiat Med 18:249-252, 2000

5. Bollar A, Allut AG, Prieto A, Gelabert M, Becerra E: Sinus pericranii: radiological and etiopathological considerations. Case report. J Neurosurg 77:469-472, 1992

6. Brisman JL, Niimi Y, Berenstein A: Sinus pericranii involving the torcular sinus in a patient with Hunter's syndrome and trigonocephaly: case report and review of the literature. Neurosurgery 55:433, 2004

7. Brook AL, Gold MM, Farinhas JM, Goodrich JT, Bello JA: Endovascular transvenous embolization of sinus pericranii. Case report. J Neurosurg Pediatr 3:220-224, 2009

8. Brown JA, Woldenberg L, Velasco ME: Recurrent sinus pericranii in a 14-year-old boy. Childs Nerv Syst 3:185-187, 1987

9. Burrows PE, Konez O, Bisdorff A: Venous variations of the brain and cranial vault. Neuroimaging Clin N Am 13:1326, 2003

10. Buxton N, Vloeberghs M: Sinus pericranii. Report of a case and review of the literature. Pediatr Neurosurg 30:96-99, 1999

11. Carpenter JS, Rosen CL, Bailes JE, Gailloud P: Sinus pericranii: clinical and imaging findings in two cases of spontaneous partial thrombosis. AJNR Am J Neuroradiol 25:121-125, 2004

12. Choux M, Gomez A, Choux R, Vigouroux RP: Diagnostic and therapeutic problems concerning tumors of the vault. Childs Brain 1:207-216, 1975

13. Chowdhury FH, Haque MR, Kawsar KA, Sarker MH, Momtazul Haque AF: Surgical management of scalp arteriovenous malformation and scalp venous malformation: an experience of eleven cases. Indian J Plast Surg 46:98-107, 2013

14. Curnes JT: Sinus pericranii: demonstration using threedimensional surface shading. J Comput Assist Tomogr 26:285-286, 2002

15. David LR, Argenta LC, Venes J, Wilson J, Glazier S: Sinus pericranii. J Craniofac Surg 9:3-10, 1998

16. Desai K, Bhayani R, Nadkarni T, Limaye U, Goel A: Developmental deep venous system anomaly associated with congenital malformation of the brain. Pediatr Neurosurg 36:37-39, 2002

17. Drosou A, Benjamin L, Linfante I, Mallin K, Trowers A, Wakhloo AK, et al: Infantile midline facial hemangioma with agenesis of the corpus callosum and sinus pericranii: another face of the PHACE syndrome. J Am Acad Dermatol $\mathbf{5 4 : 3 4 8 - 3 5 2 , 2 0 0 6}$

18. Gandolfo C, Krings T, Alvarez H, Ozanne A, Schaaf M, Baccin CE, et al: Sinus pericranii: diagnostic and therapeutic considerations in 15 patients. Neuroradiology 49:505-514, 2007

19. Grossekettler F: Sinus pericranii. Roentgenpraxis 2:368373,1930

20. Heinke W: Die chirurgischen Krankheiten des Kopfes. Dtsch Chir 31:56-66, 1882

21. İnci $S$, Turgut M, Saygi S, Gürçay Ö: Sinus pericranii associated with epilepsy. Turk Neurosurg 6:21-24, 1996

22. Kessler IM, Esmanhoto B, Riva R, Mounayer C: Endovascular transvenous embolization combined with direct punction of the sinus pericranii. A case report. Interv Neuroradiol 15:429-434, 2009

23. Koshu K, Takahashi S: Laterally situated sinus pericranii. Report of two cases with marked diploic veins. Neuroradiology 21:219-221, 1981 
24. Lasjaunias P, Garcia-Monaco R, Rodesch G, Terbrugge K: Deep venous drainage in great cerebral vein (vein of Galen) absence and malformations. Neuroradiology 33:234-238, 1991

25. Luker GD, Siegel MJ: Sinus pericranii: sonographic findings. AJR Am J Roentgenol 165:175-176, 1995

26. Macit B, Burrows PE, Yilmaz S, Orbach DB, Mulliken JB, Alomari AI: Cerebrofacial venous anomalies, sinus pericranii, ocular abnormalities and developmental delay. Interv Neuroradiol 18:153-157, 2012

27. Madsen JR, Robertson RL, Bartlett R: Surgical management of cutis aplasia with high-flow sinus pericranii. Pediatr Neurosurg 28:79-83, 1998

28. Marras C, McEvoy AW, Grieve JP, Jäger HR, Kitchen ND, Villani RM: Giant temporo-occipital sinus pericranii. A case report. J Neurosurg Sci 45:103-109, 2001

29. Mastin WM: Venous blood tumours of the cranium in communication with the intracranial venous circulation, especially the sinuses of the dura mater. JAMA 7:309-320, 1886

30. Mitsukawa N, Satoh K, Hayashi T, Furukawa Y, Suse T, Uemura T, et al: Sinus pericranii associated with craniosynostosis. J Craniofac Surg 18:78-84, 2007

31. Nakasu Y, Nakasu S, Minouchi K, Handa J: Multiple sinus pericranii with systemic angiomas: case report. Surg Neurol 39:41-45, 1993

32. Nakayama T, Matsukado Y: Sinus pericranii with aneurysmal malformation of the internal cerebral vein. Surg Neurol 3:133-137, 1975

33. Nomura S, Kato S, Ishihara H, Yoneda H, Ideguchi M, Suzuki M: Association of intra- and extradural developmental venous anomalies, so-called venous angioma and sinus pericranii. Childs Nerv Syst 22:428-431, 2006

34. Nozaki J, Kawano H, Kabuto M, Hirose K, Hayashi M: Lateral sinus pericranii. Surg Neurol 25:487-490, 1986

35. Ota T, Waga S, Handa H, Nishimura S, Mitani T: Sinus pericranii. J Neurosurg 42:704-712, 1975

36. Park SC, Kim SK, Cho BK, Kim HJ, Kim JE, Phi JH, et al: Sinus pericranii in children: report of 16 patients and preoperative evaluation of surgical risk. Clinical article. J Neurosurg Pediatr 4:536-542, 2009

37. Rangel-Castilla L, Krishna C, Klucznik R, Diaz O: Endovascular embolization with Onyx in the management of sinus pericranii: a case report. Neurosurg Focus 27(5):E13, 2009

38. Rozen WM, Joseph S, Lo PA: Spontaneous involution of two sinus pericranii - a unique case and review of the literature. $\mathbf{J}$ Clin Neurosci 15:833-835, 2008

39. Sadler LR, Tarr RW, Jungreis CA, Sekhar L: Sinus pericranii: CT and MR findings. J Comput Assist Tomogr 14:124-127, 1990
40. Schenk B, Brouwer PA: Bilateral frontal sinus pericranii with an intratabular course. A case report. Interv Neuroradiol 16:179-182, 2010

41. Sheu M, Fauteux G, Chang H, Taylor W, Stopa E, RobinsonBostom L: Sinus pericranii: dermatologic considerations and literature review. J Am Acad Dermatol 46:934-941, 2002

42. Söderberg M, Gunnarsson M: The effect of different adaptation strengths on image quality and radiation dose using Siemens Care Dose 4D. Radiat Prot Dosimetry 139:173179,2010

43. Stromeyer L: About sinus pericranii (translating of original 1850 text). Surg Neurol 40:3-4, 1993

44. Vaquero J, de Sola RG, Martínez R: Lateral sinus pericranii. Case report. J Neurosurg 58:139-140, 1983

45. Vinas FC, Valenzuela S, Zuleta A: Literature review: sinus pericranii. Neurol Res 16:471-474, 1994

46. Wakisaka S, Okuda S, Soejima T, Tsukamoto Y: Sinus pericranii. Surg Neurol 19:291-298, 1983

47. Witrak BJ, Davis PC, Hoffman JC Jr: Sinus pericranii. A case report. Pediatr Radiol 16:55-56, 1986

48. Wolfe TJ, Hussain SI, Lynch JR, Fitzsimmons BF, Zaidat OO: Pediatric cerebral angiography: analysis of utilization and findings. Pediatr Neurol 40:98-101, 2009

49. Yanik B, Keyik B, Conkbayir I, Kuru AA, Hekimodlu B: Sinus pericranii: color Doppler ultrasonographic findings. J Ultrasound Med 25:679-682, 2006

50. Yasuda S, Enomoto T, Yamada Y, Nose T, Iwasaki N: Crouzon disease associated with sinus pericranii: a report on identical twin sisters. Childs Nerv Syst 9:119-122, 1993

\section{Author Contributions}

Conception and design: Melloni, Pavanello, Gandolfo. Acquisition of data: Melloni, Pavanello, Antichi. Analysis and interpretation of data: Melloni, Pavanello, Antichi. Drafting the article: Melloni, Pavanello, Antichi. Critically revising the article: Melloni, Pavanello, Antichi, Severino, Piatelli, Rossi, Gandolfo. Reviewed submitted version of manuscript: all authors. Approved the final version of the manuscript on behalf of all authors: Melloni. Study supervision: Pavanello, Severino, Ravegnani, Piatelli, Cama, Rossi, Gandolfo.

\section{Correspondence}

Ilaria Melloni, Department of Neurosurgery, University of Genoa, Largo Rosanna Benzi, 16100 Genoa, Italy. email: ilariamel@ yahoo.it. 